\title{
Evaluation of cellular immune response provoked by experimental infection with Cryptosporidium spp. in mice

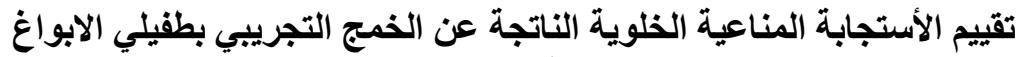 \\ الخبيئة في الفئران النمان
}

\author{
Harith S.J. AL-Warid \\ Souhaila H. Mahmood \\ * Ihsan M. Alsaqur \\ College of Science/ University of Baghdad \\ * Biological Researches Unit for Tropical Disease/ College of Science/ University of Baghdad

\begin{abstract}
Experimental infection was induced in immunosupreesed and non-immunosupressed mice using inoculation of two different Cryptosporidium spp. isolates: faecal origin and river water origin; then the infectivity rate and cellular immunological status were examined in these groups of mice. The results indicated that these two isolates induced experimental infection in immunosuppressed and non-immunosuppressed mice with no significant differences in infectivity rate between groups. Immunosuppressed mice infected with feacal or water origin oocyst showed low and significant values of transformed lymphocytes $8.68 \% \pm 0.65 \%, 9.18 \% \pm$ 1.09 respectively and phagocytic index $10.1 \% \pm 1.66$ and $11.2 \% \pm 0.19$ respectively. It concludes that lymphocyte transformation and phagocytosis index are good indicators to evaluate the cellular immune response in infected experimental mice with Cryptosporidium.
\end{abstract}

Key words: cellular immune, Cryptosporidium

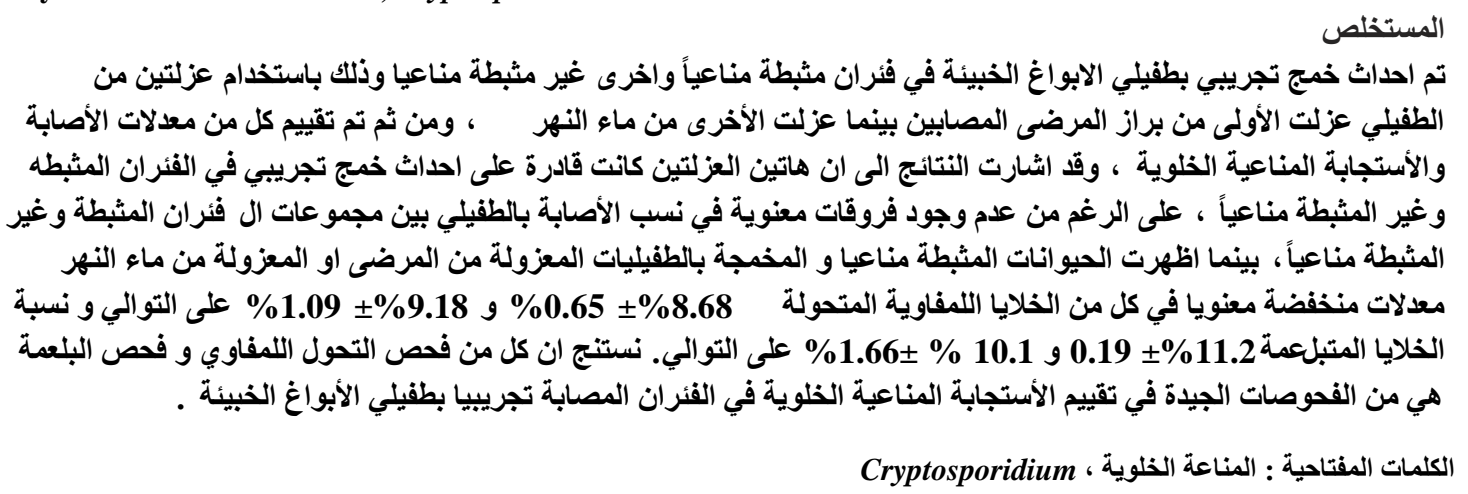

\section{Introduction}

Cryptosporidium spp. are eukaryotic protozoan of the Phylum Apicomplexa [1], more than twenty species of Cryptosporidium have been described from a variety of vertebrates (the parasite has been identified in greater than 150 vertebrate hosts) including mammals, birds, reptiles and fish [1-4]. Infection with this parasite usually presenting as a gastroenteritis-like syndrome, disease ranges in seriousness from mild to severe, signs and symptoms depend on the site of infection and nutritional and immune status of the host: evidence is also emerging that the clinical picture may vary with infecting species [5].

Several sensitive rodent models have been developed, standardized, and optimized over the last two decades [6]. The majority of investigators, presumably for reasons of availability and costs, continue to use either the neonatal mouse or the immunosuppressed adult mouse, which have major limitations. Although cryptosporidiosis occurs in most vertebrates, human cryptosporidiosis is quite distinct from that seen in other mammals. The infection in humans induces serious symptoms of gastrointestinal illness lasting several days in all age groups. Whereas infections caused acute watery diarrhea only in neonatal ruminants and piglets, no symptoms are observed in most other infected animals of any age [7]. Because of these differences, different animal models are often required for different types of scientific studies. 
The aim of this study is to evaluate the cellular immune response using lymphocyte transformation and phagocytic index in mice infected with toqw isolates of Cryptosporidium.

\section{Materials and Methods}

\section{Isolation of the Cryptosporidium spp}

Cryptosporidium spp was isolated from four high positive human faecal samples and two high positive water samples these samples were used for preparation the infected dose after concentration with Sheathers's sugar solution [8]:

1. Sheathers's sugar solution was prepared as following: $500 \mathrm{gm}$ of sucrose was added to $320 \mathrm{ml}$ of tap water and boiled, when the solution is clear, $6.5 \mathrm{gm}$ of phenol was added and gently stirred.

2. Approximately $1.5 \mathrm{ml}$ of sample was added, using conical tube that holds $12 \mathrm{ml}$, and then Sheathers's sugar solution was added to the $(9 \mathrm{ml})$ mark on tube.

3. The mixture was stirred with an applicator stick.

4. The balance of tube was filled with Sheathers's sugar solution leaving only about $1.5 \mathrm{~cm}$ open at the top.

5. The tube was centrifuged for 5 to 10 minutes at $1000 \mathrm{rpm}$.

6. Several loopfuls of material were removed from the top layer; this is where the parasites, if present, will be located.

The Oocyst from the different two origins were counted with haemocytometer, the final concentration for each faecal and water samples were adjusted to500 oocyst per $(1 \mathrm{ml})$ phosphate buffer saline.

$$
\text { No. of Oocyts in } 1 \mathrm{ml}=\text { No. of counted Oocysts } \times 1000
$$

8

\section{Animals}

Forty male mice aged 8-10weeks were obtained from "The National Centre for Drug Control and Researches/ Baghdad/ Iraq". Animals were separated into two groups each group consists of 20 mice the; first group injected with $1.5 \mathrm{mg}$ dexamethasone subcutaneously twice a week for eight weeks to develop immunodeficiency (immunosupressed mice) [10]; the second group not injected with any Immuosuppressed drugs( Non-Immunosupressed mice).

Each group then separated in to two sub-groups each sub-group consisting ten animals and were orally administrated using special catheter as following:

- Immunosupressed group 1: were treated with 100 faecal origin oocyst/ $0.2 \mathrm{ml}$

- Immunosupressed group 2: were treated with 100 water origin oocyst/ $0.2 \mathrm{ml}$.

- Non-Immunosupressed group 3: were treated with 100 faecal origin oocyst/ $0.2 \mathrm{ml}$.

- Non-Immunosupressed group 4: were treated with 100 water origin oocyst/ $0.2 \mathrm{ml}$.

- Control group: Ten mice were added as a control group.

Faecal samples from animals belonging to each group except the last group were collected and examined after 3, 5, 7, 9, 11, 13, 15 days post infection using the Modified Ziehl-Neelsen staining [1].

\section{Immunological parameters}

After 15 days post infection the following tests were done:

Lymphocyte transformation assay: Method of Shubber \& Al-Allak, 1986[10] was followed.

1. Blood was taken from heart of infected and non infected mice using a sterile $1 \mathrm{ml}$ syringe containing heparin.

2. Blood for each sample was divided into two tubes as following:

Tube I: contained $200 \mu \mathrm{l}$ blood $+250 \mu \mathrm{l}$ complete RPMI media

Tube II: contained $200 \mu \mathrm{l}$ blood $+250 \mu \mathrm{l}$ complete RPMI media $+250 \mu 1$ Mitogen.

3. Tubes were agitated carefully, and were incubated at $37^{\circ} \mathrm{C}$ for three days.

4. Tubes were centrifuged for 10 minutes at $2000 \mathrm{rpm}$, supernatant was aspirated and discarded

5. Hypotonic solution $5 \mathrm{ml}$ was added to each tube, and then tubes were incubated at $37^{\circ} \mathrm{C}$ for 50 minutes.

6. Fixative was added for each tube after centrifugation, the tubes were kept at $4^{\circ} \mathrm{C}$ for 15 minutes.

7. Step 6 was repeated 3-4 times without keeping at $4^{\circ} \mathrm{C}$.

8. Slide was prepared from the cell suspension, and stained with Geimsa stain. 


\section{Lymphocyte transformation $=\frac{\text { No. of Blast cell }}{1000} \times 100$ \\ Phagocytosis Index \\ 1000 \\ This test was done according to Furth et al., 1985[11].}

Bacteria cultivation: Staphylococcous areus was cultivated on nutreint agar, at $37^{\circ} \mathrm{C}$ for 24 hours, the bacteria was harvested and washed three times using phosphate buffer saline, then suspend with PBS to a final concentration $1 \times 10^{4}$ bacteria / $\mathrm{ml}$, then it was separated into small sterile container and kept in freezer.

Blood: Blood was taken from heart of mice using a sterile $1 \mathrm{ml}$ syringe containing heparin. , and it was put in silica coated tubes.

\section{Method}

1. About $100 \mu$ l of bacterial suspension was added to a test tube containing $100 \mu$ lof blood.

2. Tubes were incubated at $37^{\circ} \mathrm{C}$ for 30 minutes.

3. Smear was prepared from the mixture(bacterial suspension with blood)

4. Smear was air dried.

5. Stained with Geimsa stain.

Phagocytosis index $=$

No. of pahgocytic cell

500 cell (phagocytic and non phagocytic)

\section{Statistical Analysis}

Experimental data were presented in terms of observed numbers and percentage frequencies, and then analysed by SPSS 10.01 using the followings:

1. Test of proportion: $Z$ value $\leq 0.05$ was considered statistically significant.

2. ANOVA: $P$ value $\leq 0.05$ was considered statistically significant.

\section{Results and discussion}

Mice were used in this study, to evaluate the immune response, and advancement parameters of infection of two Cryptosporidium spp isolates (faecal origin and water origin). The mouse model represents a competitive alternative for many reasons: less expensive and labor-intensive than using cattle, can be used in any laboratory with basic microbiological containment and housing facilities for mice. In addition, processing of murine feces (which is solid) involves working with substantially smaller volumes of material than when working with bovine diarrhea, and this reduces the chance of accidental infection. Another important factor is that the mouse feces contains relatively little fat, so that the steps often used in the purification of oocysts from calf feces to remove fat, involving ether or acid treatment, are not required [12].

Dexamethasone was used in the present animal design to immunosuppressed two groups of mice because it was considered as a good immunosuppressive agent in several studies dealing with Cryptosporidium spp infection especially in rat and mice model [13,14], Hair of immunosuppressed animals had deteriorated, and bleeding of skin was observed after 18 day of immunosuppression in the present study Fig.(1).

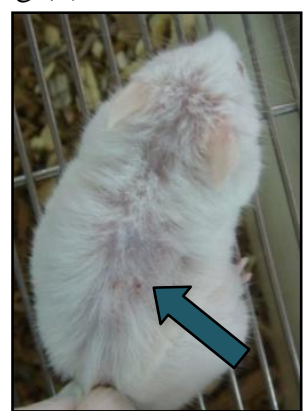

$\mathbf{A}$

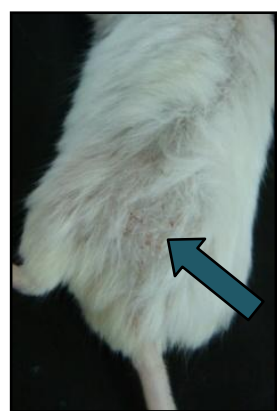

B

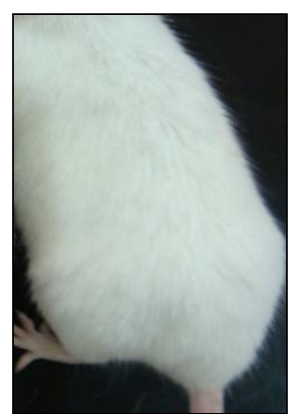

C

Fig.(1): Hair of mice belong to different experimental groups after 18 days of immune suppression
A: Hair loss in Immuno suppressed group 1
B: Hair loss in Immuno suppressed group 2
C: No hair loss in Non-immuno suppressed mice 
Infection is initiated when the host ingests oocysts [15], so oral inoculation were used in this study .The previous study showed that the infection with Cryptosporidium spp may initiate by using 2-10 oocyst [16], but this number of oocyst may not show typical symptoms of cryptosporidiosis [17] induced experimental infection using 50 oocyste, others used $10^{3}, 10^{4}$ and $10^{5}$ oocyst $[18,19]$ depend on the species of parasites and the experimental host, so the determination of oocyte dose is important to guarantee the best infection with Cryptosporidium spp. In the present study 100 oocysts was with the acceptable range of oocyst to create experimental infection which showed $40-80 \%$ of immunosuppressed and non immunosuppressed BALB/c mice comparing with $50 \%$ in neonatal SwissWebster mice using inoculation of 100-500 oocysts of C.parvum [20].

Immunosuppressed mice belonge to group 1 showed maximum number of infected animal along seven times follow up 3, 5,7,9,11,13,15 days after infection, smears was positive in 7 animals in day three of infection and 8 in the other six times follow up. Similar results was seen in Immunosuppressed mice belonged to group 2, smear was positive in 7 animal in day 3,5 and 15 of infection and 8 animals in the other five times follow up, while both group 3 and group 4 of Non-immunosuppressed mice showed the lowest number of infected animal along seven times follow up, smears was positive in 4 animals in day 3 and 7 in day 5 and 15 of infection and 6 animal in the other 4 times follow up. Similar results were seen in Non-immunosuppressed mice group 4, smears was positive in 4 animals in day 3 of infection and 5 in day 5 of infection and 6 in the other five times follow up Figure (2). The statistical analyses of results showed no significant differences between the animal groups $Z \leq 0.05$. These results agreed with the experimental data which showed that the parasites can complete its developmental cycle in 3 days [20], while a study on the infectivity of C.parvum in healthy host revealed that oocyst can be detected as early as two days after inoculation [15].

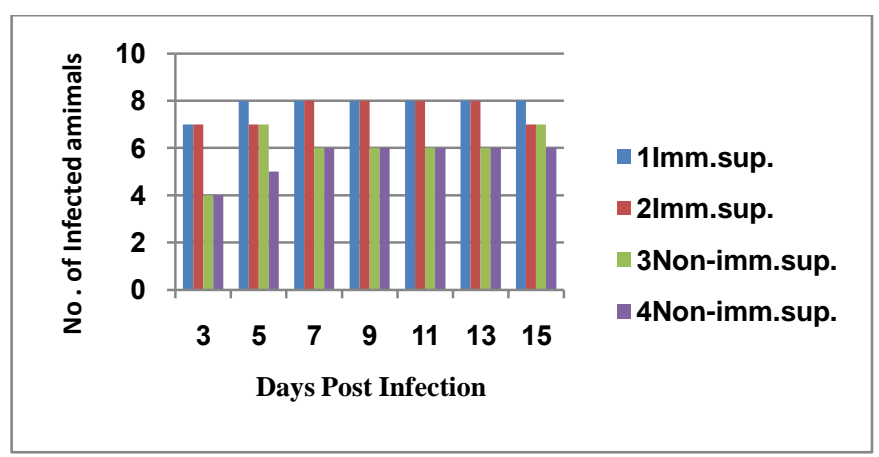

Fig.(2): Number of infected mice with Cryptosporidium along 7 times follow up post infection

On the other hand the means of transformed lymphocyte were lower in both groups 1 and 2 of immunosuppressed mice which were $(8.68 \% \pm 0.65 \%)$ and $(9.18 \% \pm 1.09)$ respectively, when it compare with control group $(12.24 \% \pm 1.48)$ and both group 3 and 4 of Non-immunosuppressed mice were $(16.79 \% \pm 2.13,16.07 \% \pm 1.44)$ respectively Figure $(3,4)$, the statistical analysis showed high significant differences between animal groups were $\mathrm{p} \leq 0.05$.

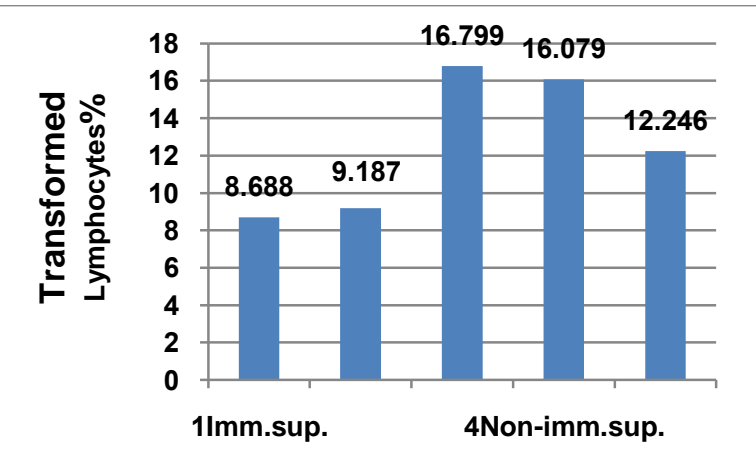

Fig. (3): Means of transformed Lymphocytes in different mice groups after 15 day of infection 


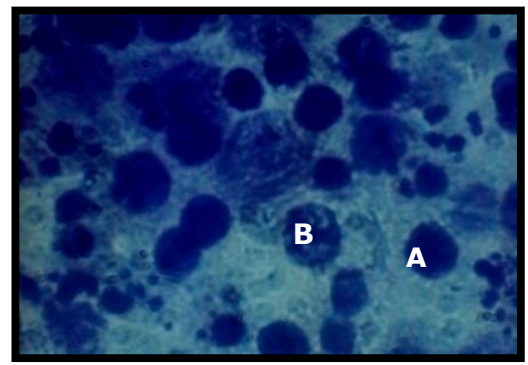

Fig. (4): Transformed Lymphocytes of mice, after 15 day of infection Geimsa stain $1000 \mathrm{X}$ A: Lymphocyte B: Lymphoblast

Means of phagocytes cells were also lower in both group 1 and 2 of immunosuppressed mice were $(10.1 \% \pm 1.66)$ and $(11.2 \% \pm 0.19)$ respectively, compared with control group $(12.2 \% \pm 1.47)$ and both group 3 and 4 of Non-immunosuppressed mice were (19.2\% \pm 2.39 and 17.4 \pm 4.37 ) respectively Figures $(5,6)$. Significant differences also showed in this test between the animal groups.

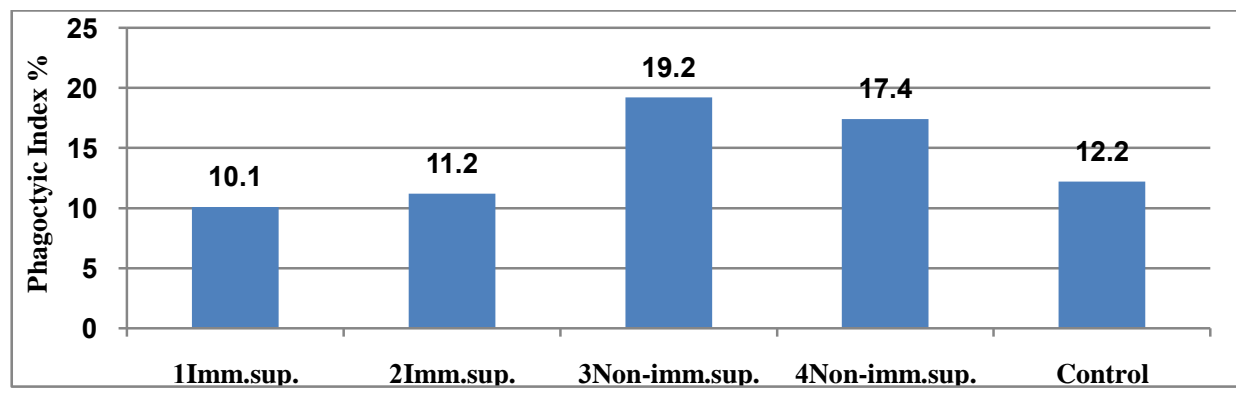

Fig.(5): Phagocytic Index in different mice groups after 15 day of infection

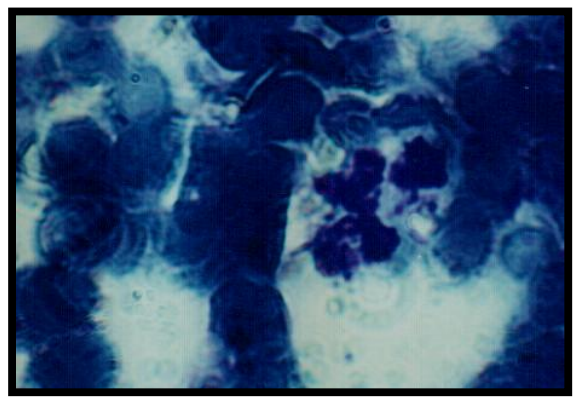

Fig. (6): Phagocytic Cell of mice, after 15 day of infection, Geimsa stain 1000 X

It is well established that prolonged administration of dexamethasone suppressed the immune system, reduced the $\mathrm{B}$ cell population in the spleen, changes the ratio of $\mathrm{CD} 4+/ \mathrm{CD} 8+$, and subsequently resulted in vulnerability to cryptosporidiosis [9]. Other studies showed that dexamethasone decreased the response of $\mathrm{T}$ lymphocyte, $\mathrm{B}$ lymphocyte and natural killer cells and antibody production and suppressed the production of serum IgG in vitro and in vitro IgG [22,23]. Results of Miller \& Schaefer [24] showed that the dexamethasone-induced immunocompromised state was associated with a greater than $90 \%$ sustained drop in circulating T-lymphocytes and a severe depletion of circulating monocytes. This suppression was related to the high oocyst shedding, War \& Villigas [25] yield $1 \times 10^{9}$ total C.paravum oocysts over a 20 day production period, these high number of oocyst observed in some immunosuppressed animal models suggested the exploitation of this phenomenon for propagation of C.parvum [12].Our results agreed with previous studies in contex of low level of both lymphocytes and phagocytotic cells in both group 1 and 2 of immunosuppressed mice accompained with the high percentage of infected animals with Cryptosporidium spp.

There were no frank depletion of both lymphocyte and macrophage in both group 1 and 2 of immunosuppressive infected mice as expected in the present study. These may due to specific immune response (anti-parasitic response) that provoked against infection with Cryptosporidium spp [24]. We 
conclude that lymphocyte transformation and phagocytosis index are good indicators to evaluate the cellular immune response in infected experimental mice with Cryptosporidium.

\section{References}

1. John, DT. and Petri, W. (2006). Medical Parasitology $9^{\text {th }}$ edition. Elsevier Inc. USA: 463 pp.

2. Bowman, DD. and Forester, AL. (2010). Cryptosporidiosis and Giardiasis in dogs and cats: Veterinary and public health importance. Exp. Parasitol. 124:121-127.

3. Feng, Y., Li, N., Duan, L. and Xiao, L. (2009). Cryptosporidium Genotype and Subtype Distribution in Raw Wastewater in Shanghai, China: Evidence for Possible Unique Cryptosporidium hominis Transmission. J. Clin. Microbiol. 47 (1): 153-157.

4. Power, M. (2010). Biology of Cryptosporidium from marsupial hosts. Exp. Parasitol.124:40-44.

5. Chalmers, RM. and Davies, A. P. (2010). Minireview:Clinical cryptosporidiosis. Exp. Parasitol.124:138-146.

6. Ren, X., Zhao, J., Zhang, L., Ning, C., Jian, F., Wang, R., Lv, C., Wang, Q., Arrowood, M. and Xiao, L. (2012). Cryptosporidium tyzzeri n. sp. (Apicomplexa: Cryptosporidiidae) in domestic mice (Mus musculus). Exp. Parasitol.130:274-281.

7. Tzipori, S. and Widmer, G. (2008). Animal Model in: Fayer, R. and Xiao, L. editors."Cryptosporidium and Cryptosporidiosis" 2ed edition. Taylors \& Francis Group., USA: 485$497 \mathrm{pp}$.

8. Zeibig, EA. (1997). Clinical Parasitology, W.B Saunders Company; Philadelphia, pp.320.

9. Rasmmussen, KR., Martin, EG., Arrowood, MJ. and Healey, MC. (1991). Effects of dexamethasone and dehydroepiandrosterone in immunosuppressed rats infected with $C$. parvum. J. Protozool. 38: 157S-159S

10. Shubber, EK. and Al-Allak, BM. (1986). Spontaneous chromosomal abreation and SCE in human lymphocytes. Effect of culture condition. The nucleus.29 (3):92-98.

11. Furth, RV., Theda, L., Liejilt, PC. (1985). In vitro determination of phagocytosis and intracellular killing by polymorphonuclear phagosytosis. Hand book of Experimental Immunology. Vol (2). Blackwell scientific publication, Oxford: $125 \mathrm{pp}$.

12. Petry, F., Robinson, HA. and McDonald, V. (1995). Murine Infection Model for Maintenance and Amplification of Cryptosporidium parvum Oocysts. J. Clin. Microbiol. (7):1922-1924.

13. Uner, A., Inceboz, T., Uysalci, M. and Gagci, H. (2003). Immune Deficiency and Cryptosporidiosis in Rats.Turk.J.Vet. Anmim.Sci. 27:1187-1191.

14. Ware, MW. and Villegas, EN. (2010). Improved Cryptosporidium oocyst propagation using dexamethasone suppressed CF-1 mice.Vet.Parasitol.168:329-331.

15. Warren, CA. and Guerrant, RL. (2008).Clinical Disease and Pathology. In: Fayer, R, and Xiao, L.editors."Cryptosporidium and Cryptosporidiosis" 2ed edition. Taylors \& Francis Group., USA.235-253 pp.

16. OIE. (2008).CRYPTOSPORIDIOSIS, OIE, terrestrial manual, OIE. Chapter, 2. 9. 4, 1192 1215.pp.

17. AL-Gelany, BA. (1998). The Epidemiology of Cryptosporidiosis in Baghdad. M.Sc. thesis, University of Baghdad.64 pp.

18. AL-Zubaidi, MTS. (2009). Some epidemiological aspects of Cryptosporidiosis in goats and Ultrastructural study. Ph.D thesis, University of Baghdad.133 pp.

19. Yuddhakaran, Y. and Veeraseatakul, P. (2002). Experimental Study on Mixed Infections of Cryptosporidium muris and C. parvum in Severe Combined Immunodeficient (SCID) and BALB/c Mice. J. Trop. Med. Parasitol. 25:1-5.

20. Ernest, JA., Blagburn, BL., Landsay, DS. and Current, WL. (1986). Infection dynamics of Cryptosporidium parvum (Apicomplexa :Cryptosporidiidae) in neonatal mice (Mus musculus). J.Parasitol.72:796-798.

21. Current, WL. and Haynes, TB. (1984). Complete development of Cryptosporidium in cell culture. Science.224: 603-605.

22. Sherwood, D., Angus, KW., Snodgrass, DR. and Tzipori, S. (1982). Experimental cryptosporidiosis in laboratory mice. Infect. Immun. 38: 471-475.

23. Rasmussen, KR., Martin, EG., Arrowood, MJ. and Healey, MC. (1993). Effects of dehydroepiandrosterone in immunosuppressed rats infected with $C$. parvum. J. Parasitol.79: 364-370.

24. Miller, T. and Schaefer, FW. (2007). Changes in mouse circulating leukocyte in C57Bl/6 mice immunosuppressed with dexamethasone for Cryptosporidium parvum oocyst production.Vet.Parasitol.149:147-157.

25. Ware, MW. and Villegas, EN. (2010). Improved Cryptosporidium oocyst propagation using dexamethasone suppressed CF-1 mice.Vet. Parasitol.168:329-331. 